\title{
Portfolio as a Viable Alternative in Writing Assessment
}

\author{
Behzad Nezakatgoo \\ Allameh Tabatabaie University, Tehran, Iran \\ Email: behzadnezakatgoo@gmail.com
}

\begin{abstract}
This study represents a quantitative attempt specifically addressing the development of EFL students' mechanics of writing in portfolio-based assessment. To carry out the study, 40 university students were selected and randomly divided into two experimental and control groups. The students in the sample were tested with the following instruments at the beginning and the end of the study: Trinity's ISE (Integrated Skills in English) Writing Test and Error Detection in Mechanics of Writing, English Language Test (CELT) was administered as pre-test to homogenize the experimental and control groups Comprehensive. The results of the study confirmed that students whose work was evaluated by a portfolio system (portfolio-based assessment) had a significant reduction in their errors in mechanics of writing when compared to those students whose work was evaluated by the more traditional evaluation system (non-portfolio-based assessment).The findings also revealed that there was a positive correlation between the dependent scorer of final examination and the independent scorer of portfolio assessment.
\end{abstract}

Index Terms - alternative assessment, portfolio, mechanics of writing, portfolio assessment

\section{INTRODUCTION}

Assessment is undergoing a paradigm shift from psychometrics to a broader model of educational assessment from testing culture to assessment culture (Gipps,1994).The underlying premise of traditional testing is that intelligence is fixed, innate and measurable. On the other hand, the underlying alternative assessment paradigm is the epistemology of mind that assumes that intelligence is flexible and subject to change. Disenchanted with the decontexualized psychometric-based testing of writing ability, the current study attempts to employ the portfolio-based writing assessment as a viable contextualized alternative approach that links teaching, learning, and assessment within a single context. It is intended to assess students more holistically and to view their development in mechanics of writing over a period of time, as well as encourage meta-cognitive and an independent attitude to learning. The portfolio-based assessment has grown out of a concern for how best to demonstrate competence in writing. The proponents of alternative assessment consider direct assessment as a more valid measure because it measures the behavior being assessed. They doubt the effectiveness of traditional testing as a valid assessment of writing ability. Olshtain (1991) asserts that effective writing requires a sound understanding of the mechanics of writing which include parts of speech, the rules of grammar and punctuation. Jack. C, Richards, Platt and Platt (1992) define mechanics of writing as those aspects of writing such as spelling, punctuation, capitalization, abbreviations, numbering which are often dealt with in the revision or editing stages of writing (p. 224). According to Murphy (1999), no system of assessment is as perfect as portfolio for writing assessment, because students are required to write, but within this requirement they can choose the topic, audience, responses in the class, revision strategies, and so on. They also are free to select from their works the pieces they want to include in their portfolios. This shows that portfolios may be used as a holistic process for evaluating course work and for promoting learner autonomy (Jack C. Richards and Willy A. Renandya, 2002). Perfect writing can be possible only when students with feedbacks which are gained from teacher and/or peers have control of writing system, mechanics of writing (punctuation, capitalization, abbreviation, numbering, and spelling) and grammar to solve the problem in writing effective compositions.

The literature on the importance of portfolio assessment is rich (Hamp-Lyons \& Condon, 2000; Defina, 1992; Yancey, 1999; Harris\& Sandra, 2001; Song\& Augest, 2002; Chang, 2008). However, most of the research reported in the literature is either of qualitative type or focuses on quantitative research to investigate writing skill in general (Song \& Augest, 2002). This study represents a quantitative attempt specifically addressing the development of EFL student' mechanics of writing in portfolio-based assessment. In order to appraise its usefulness for this purpose this study will document, analyze, compare and contrast students' performances in the portfolios, the in course pre-tests and the final examination with those of control group. The independent evaluation of student final portfolios by an independent scorer aimed at eliminating instructor bias resulting from factors other than the work submitted will be correlated with their final examination scores to explore their interrelationship. The results of the study will be examined in order to reach conclusions regarding how effective portfolio-based writing assessment is for developing mechanics of writing for students who take final examination. The study, therefore, seeks to answer the following questions and subsequent hypotheses: 
1. Are there particular errors of mechanics of writing which can be eliminated in the portfolios still emerge under examination conditions?

H1: There is a negative relationship between the frequencies of occurrence of particular error types under examination conditions and their elimination in student's portfolios.

2. Would the independent evaluation of student's final portfolios correlate positively with their final examination scores?

$\mathrm{H} 2$ : There is a positive correlation between the independent evaluation (by independent scorer) of student's final portfolios with their final examination scores.

\section{REVIEW OF RELATED LITERATURE}

\section{A. Alternatives in Assessment}

Garcia and Pearson (1994) point out that that alternative assessment consists of all of those "efforts that do not adhere to the traditional criteria of standardization, efficiency. cost-ffectiveness, objectivity and machine scorability"(p. 355).In addition to the performance of problem-solving tasks, portfolio-based writing assessment has become another alternative measure to multiple choice or timed writing tests for determining how well students understand and apply concepts. Traditional assessment has been profoundly influenced by a positivist epistemology that assumes one can achieve objectivity and consequently uncover truths about the real world. Underlying testing culture is an epistemology of intelligence which assumes that intelligence is a unitary and immutable trait, fixed, innate and measurable.

Alternative assessment is characterized by: an investigation of developmental sequences in student learning, a sampling of genuine performances that reveal the underlying thinking processes, and the provision of an opportunity for further learning. Teaching and assessment are integrated, the student is an active participant in the process of developing assessment criteria and standards. The evaluation is reported in the form of a qualitative profile.

Marx (2001) suggests portfolio-based assessment as means of individualized, student-centered evaluation has the potential to improve the complex task of student assessment, as well as to contribute to a more positive attitude toward the educational process

\section{B. Portfolio Assessment}

Arter (1989) defined portfolio as "a purposeful collection of student work that tells the story of a student's efforts, progress, or achievement. It must include student participation in the selection of portfolio content, criteria for selection, criteria for judging merit, and evidence of student self-reflection" (p. 27). The overall purpose of the portfolio is to enable the student to demonstrate to others learning and progress. The greatest value of portfolios is that, in building them, students become active participants in the learning process and its assessment.

A standardized traditional evaluation administered at the end of the term which is inflexible and tightly controlled hardly constitutes an effective method for assessing EFL students' writing ability. Hence, Portfolio-based assessment offers a viable alternative to traditional, standardized, high stakes testing. It provides a means for those students at risk for academic failure to demonstrate progress within a format less restrictive and inflexible than the traditional means.

Varvus (1990) asserts that portfolio must be systematic, organized evidence which is used by the teacher and student to measure growth of knowledge, skills, and attitudes. The objectives and contents for the portfolios must be negotiated by individual teachers and students rather than set by authorities. Students need to participate in developing the criteria and creating the rubric that is used to grade their work. Ou (2004) indicates that the following features should be considered for developing rubrics of portfolio assessment: degree of achievement of a learning goal, degree to which a student shows personal characteristics, the degree of collaboration with others, and capability to utilize resources. The major impact of portfolio assessment is the development of self-assessment ability in the students. Therefore, the goal of portfolio assessment is to cultivate student self-assessment and development abilities, and not limited to student evaluation only (Kuo, 2004; Popham, 2002, cited in chang, 2008). O’Malley and Chamot, (1990) believe that the development of self-assessment can have several outcomes for the student: students take responsibility for knowing where they are with regard to learning goals; students broaden their view of what is being learned; and students begin to see language learning as a process. The present study is also concerned with the use of portfolios for developing students' self-assessment of mechanics of writing in an EFL context.

\section{Challenges to Portfolio Assessment: Reliability and Validity}

Despite its potential benefits for curriculum and assessment, portfolio assessment has been criticized by psychometric camp for its affiliation with alternatives in assessment. Brown and Hudson (1998) summarized major challenges leveled against portfolio assessment: the issues of design decision, logistics, interpretation, reliability, and validity. Song and Augest (2002) indicate that of great concern are the assessment's time-consuming nature, and the issues of reliability and validity. Validity is concerned with the extent to which an instrument measures what it is supposed to measure. On the other hand, reliability refers to the consistency of measurement across students or across the body of work of a single student. Because standardizing portfolio content and scoring guides has been problematic, the portfolio should not be discarded as a measuring instrument. Hamp-Lyons and Condon (2000) believe that both reliability and validity are necessary and must be established "if portfolio-based assessments are to grow and to replace less satisfactory ones" 
(p. 136) since only these types of data can convince bureaucrats. Williams (2000) believes that unreliability and lack of validity in procedures will cause portfolio assessment lose its fairness and credibility.

Herta-Mcias (1995) points out that the proponents of alternative assessment suggest not to overlook these criteria, for any high quality assessment must adhere to them. Rather, the suggestion is that we apply new words that have been borrowed from the literature on qualitative research. Concerns with validity and reliability of assessment instruments have been addressed in qualitative research through the use of the term trustworthiness. An instrument is deemed to be trustworthy if it has credibility (i.e., truth value) and auditability (i.e., consistency) (p.9).She further adds that Reliability, or consistency, in qualitative research is often ensured through yet another means, triangulation. In qualitative research, triangulation refers to the combination of methodologies to strengthen a study design (Patton, 1987). When applied to portfolio assessment, triangulation refers to multiple collections of data through different writing drafts and thick description of the portfolio writing procedures. There is evidence that portfolios inform students, as well as teachers and parents, and that the results can be used to improve instruction, another major dimension of good assessment (Gomez, Grau, \& Block, 1991). This is in line with the idea of as consequential validity which maintains that a major determinant of the validity of an assessment measure is the consequence that the measure has upon the student, the instruction, and the curriculum (Linn, Baker, \& Dunbar, 1991). Moss (1994) indicates that alternative assessment, specifically portfolio-based writing, can broaden practitioners and even psychometricians' understanding of why decontextualized approaches are no longer fair and workable.

\section{METHOD}

The current study investigates the effects of portfolio-based assessment on the development of mechanics of writing in EFL students' final examination scores. Due to some limitations, the intact classes were used in a quasi-experimental design. The participants for the study were recruited from among the students who were enrolled in second-semester freshman English composition course at E.C.O. College of Insurance. Initial enrollment in this course totaled 68 students. Out of 68 examinees, the researcher finally nominated 40 participants and randomly divided them into two experimental and control groups. To be confident that there were no significant difference among the subjects of the Experimental Group (EG) and Control Group (CG) regarding the variables under investigation, both groups were pretested at the beginning of the experiment. The students in the sample were tested with the following instruments at the beginning and the end of the term: Trinity's ISE (Integrated Skills in English) Writing Test. The students were additionally tested with Error Detection in Mechanics of Writing. In order to appraise the homogeneity of the experimental and control groups Comprehensive English Language Test (CELT) was employed as a pre-test at the beginning of the term. All students have completed at least one previous three-credit composition course; approximately all of these students have also completed an additional Intermediate General English course. None of the students have prior experience with portfolios. Both groups involved in this study were taught by the same teacher in order to provide uniformity of instruction. Therefore, the researcher and the instructor were the same.

\section{A. Data Collection Procedure}

During the second week of the term, students in classes of English writing at E.C.O. College of Insurance received information about the nature of this study and were invited to participate. Students who agreed to take part in the study indicated so by signing consent forms. After completing the consent forms, all students were administered Comprehensive English Language Test (CELT), Trinity's ISE (Integrated Skills in English) Writing Test and Error Detection in Mechanics of Writing. Since English was the language of instruction at E.C.O. College of Insurance, the students were mostly at intermediate level. Both groups involved in this study were taught in the same manner and by the same instructor in order to provide uniformity of instruction. Therefore the instructional methods, textbooks and assignments in both the experimental and the control groups were identical.

In compliance with the class syllabus, the instructor taught students how to shape their college writings. Instruction followed the writing-as-process approach as far as possible. All students completed six assigned essays, and a post-test timed writing during the 16-week semester.

As is common in a writing class with a traditional (non-portfolio) method of evaluation in place, the control group turned in each essay as it was due, and the instructor marked and commented on each essay and then assigned it a grade. In the experimental group, portfolio evaluation was established. Students turned in their essays and writings on the due date, but no grade was recorded at that time. They submitted one draft each session they met the teacher, selected from among three writing tasks namely Essay writing, letter writing and creative writing provided at the beginning of the procedure. They received respective feedbacks (evaluation scales) by the next session that the class met (See appendix B). Students were credited for any revisions made. At certain points during the term, the instructor directed revision by focusing students' attention on certain strategies, such as sentence combining, strengthening weak verbs, writing effective introductions, titles, mechanics of writing (punctuation, capitalization, abbreviation, spelling, grammar, and use of numbers). Written feedbacks were emailed to students within two days; consequently, students in portfolio-based group had enough time to reflect on their writings and polish them before the next session met. (See appendix $\mathrm{C}$ for a sample draft). Students could continue to work on previously written papers until the end of the term. At the end of the term, students presented a portfolio of work to the instructor for evaluation and the term grade. The portfolio consisted 
of two polished papers (final drafts) along with first, second and third drafts for each paper respectively written during the term, and a meta-analytical cover letter. Students selected the two papers which represented the best of their work of the term. Students were encouraged to extensively revise these papers in the meantime. All prewriting, drafts, and evidences of revision for each of the two papers were included in the portfolio. The purpose of the cover letter was to allow students to reflect upon their writing processes in general, and to justify the inclusion of the papers which they had selected as representative of their best work. (See Appendix C for a copy of the instructions for compiling portfolios which were given to students). In order to eliminate instructor bias resulting from factors other than the work submitted (e.g., attendance, participation, student disposition toward the class or teacher) (Baker, 1993); an independent scorer were invited to evaluate final assessment of portfolios. During the last week of the term, all students were posttested with the same instruments used in pre-testing.

In order to gather the data necessary for this study, the Comprehensive English Language Test (CELT) were completed by both groups at the beginning of the semester. The students were additionally administered the Trinity's ISE (Integrated Skills in English) Writing Test and Error Detection in Mechanics of Writing at the beginning and at the end of the semester.

\section{B. Data Analysis}

As the first step in the data analysis the researcher tried to select a homogeneous sample of the population. A preliminary examination for homogeneity of the experimental and control groups was conducted with 68 candidates bearing almost the same background of English proficiency. The test scores obtained from the performance of subjects on the Comprehensive English Language Test (CELT).To have a more homogeneous group of candidates for the main phase of the study, high scorers and low scorers were eliminated from the main framework of the study. Almost +1 and -1 standard deviation from the mean score is the valid and reliable way of selecting homogenous sample population, hence, out of 68 examinees, the researcher finally nominated 40 participants and randomly divided them into two experimental and control groups.

TABLE 1

Descriptives

\begin{tabular}{|c|c|c|c|c|c|c|c|c|}
\hline & \multirow[b]{2}{*}{$\mathrm{N}$} & \multirow[b]{2}{*}{ Mean } & \multirow{2}{*}{$\begin{array}{c}\text { Std. } \\
\text { Deviation }\end{array}$} & \multirow{2}{*}{$\begin{array}{l}\text { Std. } \\
\text { Error }\end{array}$} & \multicolumn{2}{|c|}{$\begin{array}{l}\text { 95\% Confidence Interval for } \\
\text { Mean }\end{array}$} & \multirow[b]{2}{*}{ Minimum } & \multirow[b]{2}{*}{ Maximum } \\
\hline & & & & & Lower Bound & Upper Bound & & \\
\hline Male & 34 & 58.2813 & 7.0949 & 1.2542 & 55.7233 & 60.8392 & 47.00 & 75.00 \\
\hline Female & 34 & 58.7813 & 8.7279 & 1.5429 & 55.6345 & 61.9280 & 43.00 & 75.00 \\
\hline Total & 68 & 58.5313 & 7.8941 & .9868 & 56.5594 & 60.5031 & 43.00 & 75.00 \\
\hline
\end{tabular}

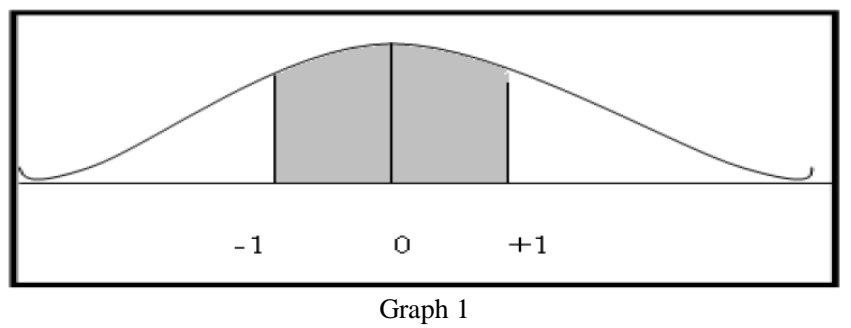

High scores and low scores were eliminated from the main framework

The researcher conducted a One Way ANOVA including the Levene Test to approve of the homogeneity of both experimental and control groups in terms of their proficiency based on their scores on Comprehensive English Language Test (CELT). Table 2 reveals the results of the Levene statistical test on Comprehensive English Language Test (CELT). The Levene statistic was 3.022 with the significance of 0.000 . The value of 3.022 is the indicative of a group of candidates with almost the same homogeneity of variances performing the Test of CELTA.

TABLE 2

TEST OF HOMOGENEITY OF VARIANCES DERIVED By SPSS SOFTWARE

Test of Homogeneity of Variances

\begin{tabular}{|c|c|c|c|}
\hline $\begin{array}{l}\text { Levene } \\
\text { Statistic }\end{array}$ & df1 & $\mathrm{df} 2$ & Sig. \\
\hline 3.022 & 1 & 66 & .000 \\
\hline
\end{tabular}


In order to make doubly sure of the homogeneity of both experimental and control groups, the ANOVA table is presented here.

TABLE 3

ANOVA

\begin{tabular}{|c|c|c|c|c|c|}
\hline & $\begin{array}{l}\text { Sum of } \\
\text { Squares }\end{array}$ & df & Mean Square & $\mathrm{F}$ & Siq. \\
\hline Between Groups & 4.000 & 1 & 4.000 & \multirow[t]{3}{*}{.063} & \multirow[t]{3}{*}{.802} \\
\hline Within Groups & 3921.938 & 66 & 63.257 & & \\
\hline Total & $3925.938^{a}$ & 67 & & & \\
\hline
\end{tabular}

a. The table indicates that the mean differnce between the two groups of candidates is not significant at all. Hence the partisipants in this study are completely homogeneous.

As for the phase of the statistical procedures which is devoted to the approval of difference between the Experimental and Control Groups in error detection of mechanics of writing. The Paired-samples t-test was employed because the trait to be tested was of the same nature for both groups. According to Hatch and Farhady (1982), the t-test is probably the most widely used statistical test for the comparison of two means because it can be used with very small sample sizes. To go through the procedure and compare the results of two groups a paired t-test was used to determine whether there were significant differences between the two groups on each of these two variables. The researcher employed $t-$ tests on the pretest measures for Trinity's ISE (Integrated Skills in English) writing and error detection in mechanics of writing. Regarding the first research question, the findings represented in the tables 4 and 5 indicates difference between the performance of both experimental and control groups in dealing with errors using mechanics of writing.

1. Are there particular errors of mechanics of writing which can be eliminated in the portfolios still emerge under examination conditions?

H1: There is a negative relationship between the frequencies of occurrence of particular error types under examination conditions and their elimination in student's portfolios.

\section{T-Test}

TABLE 4

\section{Paired Samples Correlations}

\begin{tabular}{|ll|r|r|r|}
\hline & N & Correlation & Sig. \\
\hline Pair & $\begin{array}{l}\text { Error Detection in } \\
\text { Mechanics of Writing } \\
\text { of both experimental } \\
\text { and Control Groups }\end{array}$ & 20 & -.475 & .002 \\
\hline
\end{tabular}

TABLE 5

Paired Samples Test

\begin{tabular}{|c|c|c|c|c|c|c|c|c|c|}
\hline & & \multicolumn{5}{|c|}{ Paired Differences } & \multirow[b]{3}{*}{$t$} & \multirow[b]{3}{*}{ df } & \multirow[b]{3}{*}{$\begin{array}{c}\text { Sig. } \\
\text { (2-tailed) }\end{array}$} \\
\hline & & \multirow[b]{2}{*}{ Mean } & \multirow[b]{2}{*}{$\begin{array}{c}\text { Std. } \\
\text { Deviation }\end{array}$} & \multirow{2}{*}{$\begin{array}{l}\text { Std. } \\
\text { Error } \\
\text { Mean }\end{array}$} & \multicolumn{2}{|c|}{$\begin{array}{c}95 \% \\
\text { Confidence } \\
\text { Interval of the } \\
\text { Difference } \\
\end{array}$} & & & \\
\hline & & & & & Lower & Upper & & & \\
\hline $\begin{array}{l}\text { Pair } \\
1\end{array}$ & $\begin{array}{l}\text { Error Detection in } \\
\text { Mechanics of Writing of } \\
\text { both experimental and } \\
\text { Control Groups }\end{array}$ & 8.3000 & 3.8908 & 6152 & 9.5443 & 7.0557 & 13.5 & 19 & .000 \\
\hline
\end{tabular}

The $t$ value of 13.5 reported in table 5 in a two-tailed study is the indicative of the significant difference between the performances of both groups. This means that students in portfolio-based group outperform the students of nonportfolio-based group. The number of the errors in portfolio-based group under examination conditions was less than that non-portfolio-based group. Accordingly, this substantiates with evidence the soundness of the first hypothesis.

The final phase of the statistics is devoted to the correlation analysis of the obtained data. According to Hatch and Farhady (1982), in correlation studies, researchers are interested in determining the degree of relationship between pairs 
of two or more variables, in other words, correlation studies allow us to determine the extent to which scores on one test are associated with scores on another test. In order to answer the second research question, Bivariate correlation involving the Pearson-moment Product Correlation Coefficient was used.

The tables below approve of the second question and hypothesis:

2. Would the independent evaluation of student's final portfolios correlate positively with their final examination
scores?
H2: There is a positive correlation between the independent evaluations (by independent scorer) of student's final
portfolios with their final examination scores.
Correlations
TABLE 6

Descriptive Statistics

\begin{tabular}{|l|r|r|r|}
\hline & Mean & Std. Deviation & \multicolumn{1}{|c|}{ N } \\
\hline $\begin{array}{l}\text { Dependent Scorer } \\
\text { (Final Examiantion) }\end{array}$ & 4.6500 & .74516 & 20 \\
$\begin{array}{l}\text { Independent } \\
\text { Scorer(Portfolio } \\
\text { Assessment) }\end{array}$ & 4.7500 & .91047 & 20 \\
\hline
\end{tabular}

TABLE 7

\begin{tabular}{|c|c|c|c|}
\hline \multicolumn{4}{|c|}{ Correlations } \\
\hline & & $\begin{array}{c}\text { Dependent } \\
\text { Scorer (Final } \\
\text { Examiantion) }\end{array}$ & $\begin{array}{l}\text { Independent } \\
\text { Scorer(Portfolio } \\
\text { Assessment) }\end{array}$ \\
\hline \multirow{5}{*}{$\begin{array}{l}\text { Dependent Scorer } \\
\text { (Final Examiantion) }\end{array}$} & Pearson Correlation & 1 & $.640^{\star \star}$ \\
\hline & Sig. (2-tailed) & & .002 \\
\hline & $\begin{array}{l}\text { Sum of Squares and } \\
\text { Cross-products }\end{array}$ & 10.550 & 8.250 \\
\hline & Covariance & .555 & .434 \\
\hline & $\mathrm{N}$ & 20 & 20 \\
\hline \multirow{5}{*}{$\begin{array}{l}\text { Independent } \\
\text { Scorer(Portfolio } \\
\text { Assessment) }\end{array}$} & Pearson Correlation & $.640^{\star \star}$ & 1 \\
\hline & Sig. (2-tailed) & .002 & \\
\hline & $\begin{array}{l}\text { Sum of Squares and } \\
\text { Cross-products }\end{array}$ & 8.250 & 15.750 \\
\hline & Covariance & .434 & .829 \\
\hline & $\mathrm{N}$ & 20 & 20 \\
\hline
\end{tabular}

Table 7 indicates that there is positive correlation between the dependent scorer of final examination and the independent scorer of portfolio assessment. The obtained value of Pearson Correlation is 0.640 indicating a high and significant correlation between the two variables.

The results of these statistical analyses confirmed that students whose work was evaluated by a portfolio system (portfolio-based assessment) had a significant reduction in their errors in mechanics of writing when compared to those students whose work was evaluated by the more traditional evaluation system (non-portfolio-based assessment).

\section{DISCUSSION}

The development of the mechanics of writing reflected in error detection in the students' final examination might be the result of sufficient time span available during their multiple drafting. The researcher calls it gift of time that enables them to use challenging structures and mechanics of writing in their written task performance. Findings from this study indicated that writing and assessing portfolios were beneficial to students. Even if they encountered many problems in the process, they learned a lot from solving their problems and taking responsibility of their own learning. The students of portfolio-based group benefited from the reflective nature of the task. Reflection was a self-assessment tool, which helped the learner in the experimental group of the current study to look at the strength and weaknesses of a particular learning activity and consider how to improve the weakness.

The findings of the current study raised concern as for the suitability of traditional assessment for assessing writing. Hamp-Lyons \& Condon (2000) point out that these exams particularly handicap ESL students because they not only test them on unfamiliar genres and tasks, but also require them to meet standards of excellence in grammatical and mechanical accuracy they cannot reach on a first draft in 50 minutes. The purposefully selected collection of student work over time can provide clear evidence of the student's knowledge, concept development, strategies, skills, attitudes 
and efforts. A portfolio can clearly demonstrate what each student has learned and what the individual student can do. It serves to demonstrate student progress toward specific learning objectives and to inform meaningful instruction.

The traditional view of reliability is too narrow to take into account the "less standard forms of assessment" such as the portfolio. In portfolio assessment reliability is mostly concerned with fairness reflected in the degree of agreement on the design of rubric between the scorers and students. Having students involved in the rubrics gives them the feeling of responsibility for the portfolio. Extended performance and the portfolio require that readers be trained to agree and to score papers based on a common rubric that describes numerical points. If readers agree, there is a reliable rate of agreement. If readers do not agree, there is low inter-rater reliability. To address the inter-rater reliability which is one of the main problems of reliability in L2 portfolio assessment the student's final portfolios were evaluated by independent scorer to eliminate the possible bias.

\section{RECOMMENDATIONS AND SUGGESTIONS FOR FURTHER RESEARCH}

Because quantitative data are so limited in portfolio assessment studies, more studies of this nature should be replicated using other types of writing competency exams. In addition, studies with mixed designs should be conducted to further explore the effects of portfolio assessment and its validation. Research into the efficacy of portfolio-based assessment has just begun. Extensive, ongoing research is a critical component in the process of this approach's rubric standardization. Electronic portfolios, as one type of alternative assessment, allow students to review, reflect, and determine what caused them to change. Then they can use this new information to determine future learning experiences. According to McLaughlin and Vogt (1996), as the field of technology is expanding rapidly every day, opportunities for electronic portfolios as an assessment tool will continue to advance. This requires new research efforts through explorations in the world wide web to transform the practice of portfolio assessment in the years to come.

\section{APPENDIX A}

The following evaluation scale has been taken from (ISE Handbook From 2004) Integrated Skills in English examinations I, II and III.

\section{Evaluation scale for the writing skills assessment test}

6

The essay provides a well-organized response to the topic and maintains a central focus. The ideas are expressed in appropriate language. A sense of pattern of development is present from beginning to end. The writer supports assertions with explanation or illustration, and the vocabulary is well suited to the context. Sentences reflect a command of syntax within the ordinary range of standard written English. Grammar, punctuation, and spelling are almost always correct.

5

The essay provides an organized response to the topic. The ideas are expressed in clear language most of the time. The writer develops ideas and generally signals relationships within and between paragraphs. The writer uses vocabulary that is appropriate for the essay topic and avoids oversimplifications or distortions. Sentences generally are correct grammatically, although some errors may be present when sentence structure is particularly complex. With few exceptions, grammar, punctuation, and spelling are correct.

4

The essay shows a basic understanding of the demands of essay organization, although there might be occasional digression. The development of ideas is sometimes incomplete or rudimentary, but a basic logical structure can be discerned. Vocabulary generally is appropriate for the essay topic but at times is oversimplified. Sentences reflect a sufficient command of standard written English to ensure reasonable clarity of expression. Common forms of agreement and grammatical inflection are usually, although not always, correct. The writer generally demonstrates through punctuation an understanding of the boundaries of the sentence. The writer spells common words, except perhaps so-called "demons," with a reasonable degree of accuracy.

3

The essay provides a response to the topic but generally has no overall pattern of organization. Ideas are often repeated or undeveloped, though occasionally a paragraph within the essay does have some structure. The writer uses informal language occasionally and records conversational speech when appropriate written prose is needed. Vocabulary often is limited. The writer generally does not signal relationships within and between paragraphs. Syntax is often rudimentary and lacking in variety. The essay has recurrent grammatical problems, or because of an extremely narrow range of syntactical choices, only occasional grammatical problems appear. The writer does not demonstrate a firm understanding of the boundaries of the sentence. The writer occasionally misspells common words of the language.

2

The essay begins with a response to the topic but does not develop that response. Ideas are repeated frequently, or are presented randomly, or both. The writer uses informal language frequently and does little more than record conversational speech. Words are often misused, and vocabulary is limited. Syntax is often tangled and is not sufficiently stable to ensure reasonable clarity of expression. Errors in grammar, punctuation, and spelling occur often. 
1

The essay suffers from general incoherence and has no discernible pattern of organization. It displays a high frequency of error in the regular features of standard written English. Lapses in punctuation, spelling, and grammar often frustrate the reader. Or, the essay is so brief that any reasonably accurate judgment of the writer's competence is impossible.

\begin{tabular}{|l|l|}
\hline Advice to the student & $\checkmark$ \\
\hline Task Fulfilment & \\
\hline Parts of the task have not been completed_look again at the instructions & \\
\hline The draft does not meet the requirements set-you must choose a different task & \\
\hline This work does not appear to be entirely your own-you must choose a different task & \\
\hline You should add some more ideas & \\
\hline You should give more reasons/opinions & \\
\hline You should give more description & \\
\hline You need to rewrite the work with more legible handwriting & \\
\hline The style/register of your language is not appropriate to the task & \\
\hline Organisation & \\
\hline Your presentation and/or layout need to be tidied up & \\
\hline You should check your organisation and/or paragraphing & \\
\hline You need to add an introduction & \\
\hline You need to add a conclusion & \\
\hline Your work contains a lot of repetition & \\
\hline Grammar & \\
\hline You need to check the grammar of your work & \\
\hline You should use a greater range of grammatical structures & \\
\hline You need to check your word order & \\
\hline Vocabulary & \\
\hline You should use a greater range of vocabulary & \\
\hline You need to check you are using the correct words & \\
\hline Spelling/Punctuation & \\
\hline You should check the spellings of words in your work & \\
\hline You should check and improve the punctuation in your work & \\
\hline
\end{tabular}

\section{APPENDIX B}

\section{INSTRUCTIONS FOR COMPILING YOUR PORTFOLIO}

Your writing portfolio is a showcase of the best writing you have done this term. It should contain the following:

1. A table of contents

2. A reflective evaluation on your growth as a writer this term. You may wish to make specific references to other writings you have included in your portfolio.

3. Two polished, along with all revised drafts, peer evaluations, self evaluations sheets for each paper.

When grading your portfolio, I will use the evaluation form that we went over in class. You have a copy in your folder.

\section{APPENDIX C}

\section{A Sample Draft}

Task1 Draft1

The letter shows a basic understanding of the demands of letter organization, although there might be occasional digression. The development of ideas is sometimes incomplete or rudimentary, but a basic logical structure can be discerned. Vocabulary generally is appropriate for the topic but at times is oversimplified. Sentences reflect a sufficient command of standard written English to ensure reasonable clarity of expression. Common forms of agreement and grammatical inflection are usually, although not always, correct. The writer generally demonstrates through punctuation 
an understanding of the boundaries of the sentence. The writer spells common words, except perhaps so-called "demons," with a reasonable degree of accuracy.

\section{Advice to the student}

Task Fulfillment

You should add some more ideas

You should give more reasons/opinions

You should give more description

\section{Organization}

Your presentation and/or layout need to be tidied up

You should check your organization and/or paragraphing

You need to add an introduction

You need to add a conclusion

\section{Grammar}

You need to check the grammar of your work

You should use a greater range of grammatical structures

You need to check your word order

\section{Vocabulary}

You should use a greater range of vocabulary

You need to check you are using the correct words

\section{Spelling/Punctuation}

You should check the spellings of words in your work

You should check and improve the punctuation in your work

\section{REFERENCES}

[1] Arter, J.A. (1989). "Assessing Communication Competence in Speaking and Listening: a consumer's guide”. Portland. OR: Northwest Regional Educational Laboratory.

[2] Baker, Nancy Westrich. (1993). "The Effect of Portfolio-Based Instruction on Composition Students' Final Examination Scores, Course Grades, and Attitudes Toward Writing." Research in the Teaching of English 27.2 (May 1993).

[3] Brown, J. D., \& Hudson, T. (1998). The alternatives in language assessment. TESOL Quarterly, 32, 653-675.

[4] Chang, C. C. (2008). Enhancing self-perceived effects using Web-based portfolio assessment. Computers in Human Behavior, $24,1753-1771$.

[5] Defina, Allan A. (1992). "Portfolio Assessment: Getting Started." New York: Scholastic Professional Books.

[6] Douglas, D. (2000). "Assessing language for specific purposes." Cambridge: Cambridge University Press.

[7] Gipps, C. (1994). Beyond Testing: Towards a Theory of Educational Assessment. London: Falmer Press.

[8] Gomez, M., Grave, M., \& Block, M. (1991). Reassessing portfolio assessment: Rhetoric and reality. Language Arts, 68, 620628.

[9] Gurcia. G.E., \& Pearson, PD. (1994). Assessment and diversity. In L. Darling Hammond (Ed.), Review of research in education (p p. 337-391). Washington. DC: American Education Research Association.

[10] Hamp-Lyons, L., \& Condon, W. (2000). Assessing the portfolio: Principles for practice, theory, and research. Cresskill, NJ: Hampton.

[11] Harris, S. \& Sandra, M. (2001). "Portfolio use in two principal programs." Rural Educator, 23, 19-23

[12] Hatch, E. and Farhady, H. (1982). "Research Design and Statistics for Applied Linguistics." Rowley, MA: Newbury House Publishers.

[13] Huerta-Macias, A. (1995). Alternative Assessment: Responses to Commonly Asked Questions. TESOL Journal, 5(1),8-11.

[14] Kuo, S.-Y. (2004). Educational test and assessment. Taipei: Chin-Hau.

[15] LINN, R.L., BAKER, E. and DUNBAR, S. (1991) 'Complex, performance based assessment: Expectations and validation criteria', Educational Researcher, 20, 8, pp. 15-21.

[16] Marx, G. (2001). Educating children for tomorrow's world. The Futurist, 35(2), 43-48.

[17] McLaughlin, M., \& Vogt, M. (1996). "Portfolios in teacher education."Newark, NJ: International Reading Association.

[18] Moss, P. (1994). Validity in high stakes writing assessment: Problems and possibilities. Assessing Writing, 1,109-128.

[19] Murphy, S. (1999). "Assessing Portfolio." In C. Cooper \& L. Odell (Eds.), Evaluating writing (pp. 114-136). Urbana, IL: National Council of Teachers of English.

[20] Olshtain, Elite. (1991). "Functional Tasks for Mastering the Mechanics of Writing and Going Just Beyond." This chapter originally appeared in Teaching English as a Second or Foreign Language (2nd ed.) Los Angeles: University of California.

[21] O’Malley, J. \& Chamot, A. (1990). "Learning strategies in second language acquisition." New York: Cambridge University Press.

[22] O’Malley, J. \& Pierce, L. (1996). "Authentic assessment for English language learners." US: Addison-Wesley Publishing.

[23] Ou, C.-H. (2004). Educational test and assessment. Taipei: Shin-Lee.

[24] Patton. M.Q. (1987). Creative evaluation .Newbury Park, CA: Sage.

[25] Popham, W. J. (2002). Classroom assessment: What teachers need to know. Boston, MA: Allyn and Bacon.

[26] Richards, Jack. C. and J. Platt, H. Platt. (1992). "Dictionary of Language Teaching and Applied Linguistics." (2nd ed.) Longman.

[27] Richards, Jack. C. and Willy A. Renandya. (2002). "Methodology in Language Teaching: An Anthology of Current Practice." The United States of America: Cambridge University Press. 
[28] Song, Bailin. And B. August. (2002). "Using portfolio to Assess the Writing of ESL Students: A Powerful Alternative?" Journal of Second Language Writing. 11 (2002) 49-72

[29] Taylor, C.S. (1997). "Using portfolios to teach teachers about assessment: How to survive." Educational Assessment, 4(2), 123147.

[30] Varvus, L. (1990, Aug.). Put portfolios to the test. Instructor, 2(1), 49-52.

[31] Williams, J.D. (2000). Identity and reliability in portfolio assessment. In B. Sun stein \& J. Lovell (Eds.), The portfolio standard (pp. 135-148). Portsmouth, NH: Heinemann.

[32] Yancey, K. B. (1999). Looking back as we look forward: Historicizing writing assessment. College Composition and Communication, 50, 483-503.

Behzad Nezakatgoo is a PhD candidate of TEFL at Allameh Tabtabaie University, Tehran, Iran. He has taught English courses in different universities in Tehran. His areas of interest are language testing, dynamic assessment and syllabus design. He has published articles in national and international journals. 